\title{
Helping parents with the diagnosis of disability
}

1. Name and qualification: Jill Cadwgan* MBChB MRCPCH

Job title: Consultant Paediatrician in Neurodisability, Associate Clinical Researcher

Institution: Evelina London Children's Hospital, Guys and St Thomas' NHS Foundation

Trust (Kings Health Partners); Institute of Neuroscience, Newcastle University

Address: Evelina London Children's Hospital, St Thomas' Hospital, Westminster Bridge

Road, London SE1 7EH

T: 07557896447

E: Jill.Cadwgan@gstt.nhs.net

ORCID ID: orcid.org/0000-0002-1198-8400

2. Name and qualification: Jane Goodwin, BPsych PhD

Job title: Research associate

Institution: Evelina London Children's Hospital, Guys and St Thomas' NHS Foundation

Trust (Kings Health Partners); Institute of Health and Society, Newcastle University

Address: Level 3, Sir James Spence Institute, Royal Victoria Infirmary, Queen Victoria Road,

Newcastle upon Tyne, NE1 4LP

T: 01912823044

E: Jane.Goodwin@uon.edu.au

ORCID ID: orcid.org/0000-0002-5633-9148

*Corresponding author

\section{Keywords:}

Continuity of Patient Care; Adaptation, Psychological; Clinical Decision-Making/ethics, methods; Quality of Life; Parenting; Disabled Children; Patient Care

\section{Acknowledgements:}

Helen McConachie MA MPhil PhD Professor of Child Clinical Psychology at Newcastle University, Institute of Health and Society, Newcastle upon Tyne, UK.

\section{Conflict of interest}

Both authors report funding from the National Institute for Health Research under its Health Technology Assessment (NIHR HTA) Programme. The views expressed are those of the authors and not necessarily those of the NHS, the National Institute for Health Research, or the Department of Health.

Jill Cadwgan has received honoraria for lectures and developing teaching materials from pharmaceutical companies. She is the honorary secretary of BACD. 


\begin{abstract}
How the diagnosis of neurodevelopmental disability is communicated to the family has long-lasting effects. When clarification of the diagnosis takes a long time, this is particularly hard for child health professionals to manage well, and a joint understanding of the process with the family is important. Guidelines for the conduct of the diagnostic consultation are presented.
\end{abstract}

The impact on family and parents of caring for a disabled child depends on many factors, including the child's behaviours, available resources and families' coping strategies. By understanding families' individual differences, professionals can provide excellent health care but also help families to promote the child's quality of life and social participation. 


\section{Introduction}

The overall prevalence of neurodevelopmental disability in childhood is difficult to ascertain due to the variety of ways in which disability has been defined and measured, and increasing rates with age. With improved survival of premature infants, and better medical care, there is a substantial requirement for health services to support children and young people with complex medical and neurodevelopmental needs. In recent decades, both professional and carer understanding of the impact of impairment and subsequent disability has evolved from a largely medical model to an appreciation of maximizing young people's quality of life and social participation, regardless of body structure and function.

Guidelines regarding how to discuss the diagnosis of neurodevelopmental disability with the family are available; however the child and family journey through recognition of impairment through diagnosis and subsequent adaptation is complex. This review will discuss the factors affecting resolution and coping strategies, in order to offer further guidance for child health clinicians in communicating effectively with families before, during, and after the time of diagnosis.

In 2007, the adapted version of the International Classification of Functioning, Disability and Health for children and youth (ICF-CY) was published, and participation and quality of life in young people with disability are now the focus of multi-national health research, and service delivery. This shift in emphasis to include both a medical and social construct of any diagnosis is key to professionals effectively supporting families. Parents and carers look to professionals for accurate information about the characteristics and aetiology of their child's identified impairments. At the same time, their understanding of their child's needs and their desire to achieve a good outcome, allows joint development of the meaning of the child's diagnosis (Figure 1). 


\section{Before diagnosis}

In infants where there is an immediately recognized medical abnormality or need for intensive care, issues regarding survival and medical intervention are paramount; however, parents may not appreciate the possibility that their infant may survive with long-term impairment. The need to discuss possible outcomes in the neonatal period is not uncommon and where possible the consultant or most senior member of the team should be available. Junior medical staff may, however, have the initial contact with the family, particularly out of hours. Training in generic communication skills and specific scenarios (e.g., discussion of Down syndrome, or impending premature delivery) is an essential component of both undergraduate and postgraduate medical curricula. Nevertheless, adherence to guidelines and best practice in communication skills may not be universal.

A more protracted process of recognition before diagnosis is likely in the case of other developmental disabilities such as cerebral palsy, neurometabolic, neurogenetic, and pervasive developmental disorders. Although concerns may be identified early, there may be a prolonged period of investigation or assessment. With significant recent advances in diagnostic investigations, particularly with genetic investigations (initially with CGH array and now with established clinically available single gene panels for recognised clinical phenotypes, and more detailed research-based techniques such as whole genome and exome sequencing), there may be results of uncertain significance, leading to further anxiety for parents. In many cases, a definitive diagnosis may still remain elusive. In these situations, parental adaptation and reaction to the impairment (and thus opportunities to help parents cope) may have already commenced and there may be significant clinical and social support established with or without a diagnosis. On the other hand, some parents report that they feel isolated in their concerns, or that there are challenges to accessing the support they need (e.g., administrative barriers, service provision issues). 


\section{Diagnostic consultation}

The adaptation and resolution of a family with a disabled child are dependent on many factors; however, a commonly reported significant factor affecting this is the manner and circumstances of the diagnostic consultation. The diagnostic consultation presents an interesting dynamic: the parent may feel overwhelmed by emotion, and the clinician is primarily focused on the information they are providing. These two perspectives can be difficult to reconcile. Qualitative studies have identified 'see-sawing' in negotiation between carers and professionals, where judgement is made regarding how to use language, and information and prognosis given according to perceived parental reactions. For example, where a parent is despairing the clinician may hold out more hope, whereas when parents are optimistic, the clinician may be more blunt and pessimistic.

Studies demonstrate that the empathy and language of the person who disclosed the diagnosis, the arrangements made for the consultation, and subsequent follow up are the key components. Parental dissatisfaction with the diagnostic process include lack of sufficient and understandable information, dismissal of worries, lack of empathy, delay in diagnosis (and the belief that clinicians know before disclosing), lack of opportunity to ask questions, and unapproachable clinicians.

The following guidelines suggest an approach to diagnostic consultation (whether early or later in a child's life), and are based on published evidence from research in health and social sciences and guidance from the Department of Health and other organisations, including parent led organisations (e.g., National Network of Parent Carer Forums, Cerebra). Professionals must remember that each child, their family, their cultural and environmental situation are different and adapt their approach accordingly. 


\section{Guidelines for diagnostic consultation}

\section{Preparatory information}

- Understanding the family dynamics, environment and understanding of their child is important, wherever possible, accessing the shared knowledge of the whole multidisciplinary team.

- The clinician(s) who will be disclosing the diagnosis must have appropriate generic training in communication skills, but also full information and confidence in the diagnosis and family background.

\section{The consultation}

\section{Timing:}

- Realistic allocation of time is required for detailed discussion.

- Ensuring that the appointment is made as soon as possible after diagnostic investigation but that all relevant information is available.

- Giving parents realistic time scales as to when investigation results will be available.

- Ensuring that the timing allows for a further follow-up appointment promptly.

- There should be no interruptions during the consultation.

\section{Personnel present:}

- Parents prefer where possible to hear the news together. There may be other significant family members or friends that they would also like to include - either at initial or subsequent consultation. If it is not possible to have one parent or carer at the initial consultation, then arrangements must be made to discuss this with them as soon as possible.

- The number of staff present should be kept to a minimum; however, a key professional, such as a community nurse or therapist who has a good relationship with the family and availability for timely follow up, should be present. They may advocate for the family in prompting appropriate questions or clarifying medical information. 
- Where an interpreter is required, this should be arranged professionally. A family member or friend is not appropriate. Care should also be taken regarding confidentiality if the interpreter is part of the family's cultural community.

\section{Style and content of information shared:}

- Empathy, sensitivity and honesty should be conveyed during the consultation through verbal and non-verbal communication. Non-verbal cues that make the clinician appear dismissive or rushed (e.g., looking at the clock) should be avoided. Clinicians can empower parents by empathising with parents' feelings of vulnerability and highlighting what they can do for their child.

- Setting the scene at the start is important, to ensure that the parents and professionals understand the purpose of the consultation. Ask carers specifically what they understand is the purpose and specific questions they had prior to the consultation. This agenda setting builds a platform for the whole consultation, and establishes prior level of knowledge, ideas, concerns and expectations.

- Use plain, understandable language and frequently check understanding by summarizing and giving opportunity to ask questions.

- Refer to the child, by name, as an individual (not a diagnosis) and always remain positive but realistic.

- Provide current information with regards to the diagnosis, aetiology, prognosis (including walking, communication, and life expectancy), expected developmental progress, comorbidities, and availability of specialist equipment and resources.

- Facilitate positive communication with families using a variety a strategies such as:

$\circ$ Introducing then explaining medical terminology.

o Describing what 'typical' test results would be compared to the child's.

○ Sharing images (e.g., scans) to explain the cause of the child's challenges.

- Using analogies to make information more understandable. 
○ Recapping and comparing back to information-giving by clinicians in other settings.

○ Providing information about risk based on incidence data.

- Have an equivalent focus on the child's strengths as well as the diagnosis and impairment, discuss opportunities for the future, and environmental strategies to support participation. Explain the concepts that it is the environment that "disables" the child; not the child's impairment.

- Discuss positive role models, who have impairment, and acknowledge the changing societal attitude to disabled people, use examples, such as the positive media coverage of the Paralympic games, or media support to "hidden disabilities": mental health disorders and learning disabilities.

- Share positive evidence. For example, self-reported quality of life in young people with cerebral palsy being equal to quality of life of typically developing children is a powerful message for parents.

- Try to keep the child with the parents' throughout the consultation. Where this is inappropriate, for example where the child is older, ensure provision for supervision is available and ensure that at least some explanation is given to the child as soon as possible.

- When disclosing a diagnosis to an older child the following must be considered and addressed:

○ Timing and amount of information disclosed should be decided in discussion with the parents

- A suitable member of the team should be selected.

- Allowing the child to have further follow-up discussions with or without parents. They may wish to select their own friend or professional to discuss issues with. 


\section{Follow up}

- The team should recognize that much of the information shared on initial consultation may not be remembered or understood.

- Written information must be provided at the time of consultation to include contact details of professionals and sources of support information. Parents should be encouraged to write down further questions and contact professionals to ask them.

- A detailed record of the discussion should be sent to parents and copied to relevant professionals with parental consent.

- Sources of information for relatives, friends and carers should be available. Age appropriate information for the child and siblings is also essential.

○ Background medical information of child's condition.

- Statutory and voluntary services (and how to access these).

- Relevant websites and information regarding searching for medical information on the internet.

○ Financial benefits and practical support.

- Information should be updated and adapted regularly with the family's needs and the child's development.

- The family should leave with a clear plan of: "what happens next?",

$\circ$ Who will contact them and when.

○ Timing of follow-up appointment to answer questions and begin a plan of support.

- Details of any further investigations or assessments that may be required.

O Other professionals that may become involved.

\section{Impact of diagnosis}

Parental reaction and adaptation to a diagnosis is highly variable. Understanding the emotions, reaction and subsequent resolution is complex. In the past, models suggested for 
understanding this have been based around bereavement adjustment. Such models, although recognizing and explaining maladaptive responses from carers, have negative connotations. Experiencing unexpected and difficult journeys such as parenting a disabled child may cause psychological distress; yet, adversity can also be the springboard for psychological growth and wellbeing with the right support. It is important for carers and clinicians to recognize that a range of emotions is to be expected; however, practical support to enhance family functioning and adaptation should be the focus of the team around the child (see Table 1). 
Table 1 Parents' reactions to disability

\begin{tabular}{|c|c|c|}
\hline $\begin{array}{l}\text { Parental } \\
\text { reaction }\end{array}$ & Explanation & How can clinicians support parents? \\
\hline Grief & $\begin{array}{l}\text { Caring for a disabled child is often unexpected, and the initial shock can be } \\
\text { confounded by chronic sorrow for the child that the parents expected or wanted. } \\
\text { This can be particularly difficult when parents have the affected child's twin, } \\
\text { sibling, or peer group to compare them to. } \\
\text { Ambiguous loss: when a loved one is physically present but psychologically } \\
\text { absent. Parents may grieve the "absent" child they had hoped for. } \\
\text { Disenfranchised grief: Loss that is not recognised or validated by others. Parents' } \\
\text { grief about lost dreams for their child may go unrecognised. }\end{array}$ & $\begin{array}{l}\text { - Check in on families throughout their journey. There are ongoing adjustments to } \\
\text { delayed or missed milestones well beyond the diagnosis. Parents may grieve for } \\
\text { themselves as well as their child. }\end{array}$ \\
\hline $\begin{array}{l}\text { Psychological } \\
\text { distress }\end{array}$ & $\begin{array}{l}\text { Parents who have a disabled child are vulnerable to psychological distress (e.g., } \\
\text { depression), perhaps due to the emotional and physical demands they experience } \\
\text { in their caregiving role. }\end{array}$ & $\begin{array}{l}\text { - The child's level of care and appointment attendance may be an indicator of parents' } \\
\text { distress. } \\
\text { - A strength-based approach is likely to be beneficial for parents' wellbeing. } \\
\text { - Be aware that practical issues are just as important as parents' emotions. }\end{array}$ \\
\hline Burnout & $\begin{array}{l}\text { As the stressors associated with caring for a disabled child are ongoing, parents } \\
\text { are physically and psychologically vulnerable because their adaptive energy has } \\
\text { been sapped. This means they are susceptible to burnout, which can present as } \\
\text { helplessness, fatigue, listlessness, loss of empathy and oscillation between } \\
\text { avoidance and over-engagement. }\end{array}$ & $\begin{array}{l}\text { - Ensure parents have appropriate access to respite. } \\
\text { - Routine and/or enjoyable parenting tasks (sleeping, feeding, behaviour management) } \\
\text { can be challenging for parents. } \\
\text { - Lack of sleep affects parents' ability to cope, care, work, and enjoy life. }\end{array}$ \\
\hline $\begin{array}{l}\text { Traumatic } \\
\text { distress }\end{array}$ & $\begin{array}{l}\text { Trauma refers to an adverse event that shatters a person's worldview. It can be } \\
\text { experienced primarily (personally; e.g., shock at diagnosis) or vicariously } \\
\text { (exposure to others' trauma; e.g., witnessing their child's medical procedures). } \\
\text { Traumatic distress symptoms can include dissociation (e.g., feeling numb); re- } \\
\text { experiencing (e.g., dreams of the event); avoidance (e.g., avoiding places that } \\
\text { remind the person of the traumatic event); and arousal (e.g., difficulty sleeping). } \\
\text { Anticipation of trauma: hypervigilance to potential traumatic events, evoking } \\
\text { raised expectation of threat that can negatively impact decision-making. }\end{array}$ & $\begin{array}{l}\text { - Information leaflets, handbooks, and familiarisation visits are useful tools to prepare } \\
\text { families. } \\
\text { - Traumatic distress can cause parents to avoid aspects of their child's care, including } \\
\text { appointments, hospital visits, new medications. } \\
\text { - Supporting parents through treatment decision-making. }\end{array}$ \\
\hline $\begin{array}{l}\text { Meaning- } \\
\text { based coping }\end{array}$ & $\begin{array}{l}\text { When faced with negative psychological states associated with significant stress } \\
\text { or uncertainty, people may be consciously or unconsciously motivated to create } \\
\text { positive psychological states in order to gain relief. }\end{array}$ & $\begin{array}{l}\text { - Using basic counselling skills (e.g., active listening, good communication, and } \\
\text { empathy), so that parents firstly feel 'heard'. } \\
\text { - Referring parents to relevant information about the syndrome and appropriate support } \\
\text { services. }\end{array}$ \\
\hline $\begin{array}{l}\text { Psychological } \\
\text { growth }\end{array}$ & $\begin{array}{l}\text { Experiencing distress can be a catalyst for growth out of adversity (also known as } \\
\text { posttraumatic growth). Parents of disabled children report positive psychological } \\
\text { changes, such as finding: new meaning in their lives, spirituality, inner strength, } \\
\text { humility, pride, and gratitude. }\end{array}$ & $\begin{array}{l}\text { - Encouraging parents to positively reappraise their journeys. } \\
\text { - Referring parents to support groups (including those on social media) for peer learning. } \\
\text { - Empowering parents to be their child's key worker. }\end{array}$ \\
\hline
\end{tabular}

Note. Parents may identify with all or none of these reactions at any given time. It is possible to experience conflicting reactions simultaneously. 
The level of support must be sustained in the time following diagnosis. Parents may turn to the Internet for information about their child's diagnosis. This can be empowering and beneficial for discovering support avenues and learning more about disability. However, Internet health information has the potential to be inaccurate, incomplete, and/or of poor quality. Parents who have a disabled child may be susceptible to overestimating the value of low quality information and advice. This is understandable: parents are likely to want to improve their child's quality of life, or may even have the desire to 'cure' them. Yet, it leaves them vulnerable to interventions and/or treatments that may be costly, not improve their child's functioning, and/or cause harm. Both parents and clinicians can refer to national guidance (e.g., NICE) and other websites, for example, the Peninsula Cerebra Research Unit (PENCRU) evidence summaries, available on their website (http://www.pencru.org/).

Evidence demonstrates that issues of paramount importance to the family are feeding, sleeping, mobility, timely access to equipment and adaptations, personal care and hygiene, as well as how to balance the needs of all the family members. A clinician may assume the family's questions are centred on diagnosis, medical information and prognosis. Accurately ascertaining parent concerns is essential to supporting families and demonstrating empathy.

Follow-up appointments and additional referrals should be prompt, and involvement with established parent support groups for infants with disabilities may provide significant support (Figure 2).

\section{Coping with the child's disability}

The long-term impact of the child's disability on the family is dependent on multiple factors. Studies of the mental health of parents of children with an intellectual or physical disability have shown greater stress levels than are seen in other parents. Early research has focussed on maternal adaptation, reassuringly more recent literature has included fathers recognised also as primary care-givers. 
Factors influencing levels of stress on the family are both intrinsic and external. The severity of the impairment is often not a predictor of the level of stress, rather it is child factors such as ill-health or behaviour problems, lack of family and social support and family psychosocial and pre-disposing factors.

Financial pressures are a major external contributor to stress. There are the increased costs of caring for a disabled child: additional heating, higher telephone bills and the expense of a suitable vehicle for transport, as well as clothing and bedding, equipment and house adaptations. The families may have less income than they otherwise might have had, as parents are often less able to take up employment or promotion. Despite receiving some benefits, families may experience several years of financial constraint, extending in some cases even into the period after the death of a child.

Qualitative research and psychosocial models have enabled a greater understanding of the most significant stressors, the external and internal resources of family members and the cognitive coping strategies they adopt. It is important to realise that, as with any child, bringing up a disabled child is usually a very rewarding and positive experience for a family. Nevertheless, appropriate provision of services to meet the child's and family's needs is essential to family and individual well-being.

The main findings of the research on coping are as follows, and can be used to guide clinicians to help parents:

- Life events that occur in any family (e.g., redundancy or the death of a grandparent) may have greater significance in a family of a disabled child.

- The important material resources are a suitable transport vehicle and an enclosed garden allowing play without constant supervision.

- The involvement of local housing departments, flexible employment arrangements for parents and access to benefits are essential. 
- Important social resources are practical and emotional support from family and friends, including the parents of other children with disabilities. Thus, if a family is isolated, services need to help to extend the social network through schemes such as link families and play schemes.

- Poorly coordinated services (health, education and social) can themselves be a source of stress. A 'key worker' approach to service provision is recommended.

- Services should consider how to meet the particular needs of families from minority and ethnic groups, for example, the ways in which short-term breaks are offered and arranged. There remain significant challenges in the UK regarding equity of access to services.

- Knowledge and empowerment of parents reduces their stress, and enables them, in partnership with professionals to make choices in how services are provided.

- Locally and nationally developed materials can be used by families to share information with professionals, to keep track of multiple contacts, to discuss what is most important, and to make plans for the child's care.

- Negotiation of an appropriate partnership with community professionals is particularly important for parents of technologically dependent children, where the parents develop high levels of expertise.

- Services should be provided with the aim of supporting the quality of life and participation of the whole family. Respite provided in the home setting, or short breaks may significantly improve this.

- The paediatrician, although considered most helpful with providing information about the child's medical condition and developmental progress, is not widely regarded as being most helpful in relation to common consequences of impairment, such as managing behaviour problems, accessing benefits and liaising with voluntary 
organizations. In the current climate of resource limitation, models of care need to recognise and genuinely use MDT resource.

- Engaging children, their parents and families in research can empower them to make a positive difference, and being honest about the current paucity in clinical evidence enhances parent-professional relationships.

\section{Conclusion}

Empowerment of parents and carers, provision of services and adjustment of societal and individual attitude toward diversity and disability are the most important factors to improve outcome for disabled children and their families. Recognition of these factors has had a significant influence on UK health policy. Evolution of policy since the Children Act 2004 has relied increasingly on engagement and consultation with all stakeholders. The development of parent participation through the National Network of Parent-Carer Forums and input from the Council for the Disabled Children, in collaboration with medical organisations such as the Royal College of Child Health, British Academy of Childhood Disability, and British Academy of Community Child Health has allowed consultation and evaluation of the Children and Families Bill, the pilot and implementation of the SEND reforms, and multiple NICE guidelines. This engagement has enabled the shift in focus from the child's impairment to the provision of services aiming to facilitate participation and achievement in all children.

There remain significant challenges in meeting the needs of disabled children and their families, particularly in the current climate of austerity. In many consultations with parents, lack of facilities such as respite care and access to leisure activities is highlighted. Multiagency working, ring-fenced budgets for equipment and the provision of a key worker are implicit to the policies, but implementation remains patchy. 
The diagnostic process and consultation commence the engagement of children and their families with health, education, and social care services. The paediatrician's role is to provide accurate and timely diagnosis, then to support the family with co-ordination of services. Advocating for the child to support seamless provision of services and equality of access for all children, independent of their diagnosis, postcode, or chance. Maintaining upto-date knowledge of services and policy is essential for medical staff and allied health professionals working in this field. 


\section{Further Reading}

An M, Palisano RJ. Family-professional collaboration in pediatric rehabilitation: a practice model. Disabil. Rehabil. 2014; 36: 434-40.

Baird G, McConachie H, Scrutton D. Parents' perceptions of disclosure of the diagnosis of cerebral palsy. Arch. Dis. Child. 2000; 83: 475-80.

Bartolo PA. Communicating a diagnosis of developmental disability to parents:

multiprofessional negotiation frameworks. Child Care Health Dev. 2002; 28: 6571.

Broberg M. Expectations of and reactions to disability and normality experienced by parents of children with intellectual disability in Sweden. Child Care Health Dev. 2011; 37: 410-7.

Fischer M, Ereaut G. Can changing clinician-patient interactions improve healthcare quality. Health Foundation 2011: 1-60.

Graungaard AH, Skov L. Why do we need a diagnosis? A qualitative study of parents' experiences, coping and needs, when the newborn child is severely disabled. Child Care Health Dev. 2007; 33: 296-307.

Hart AR, Sharma R, Atherton M, Alabed S, Simpson S, Barfield S, Cohen J, McGlashan N, Ravi A, Parker MJ, Connolly DJ. Aetiological investigations in early developmental impairment: are they worth it? Arch. Dis. Child. 2017; 102: 100413.

King G, Chiarello L. Family-Centered Care for Children With Cerebral Palsy: Conceptual and Practical Considerations to Advance Care and Practice. J. Child Neurol. 2014; 29: $1046-54$.

McAnuff J, Boyes C, Kolehmainen N. Family-clinician interactions in children's health services: a secondary analysis of occupational therapists' practice descriptions. Health Expect. 2015; 18: 2236-51. 
McLaughlin J. Exploring diagnostic processes: social science perspectives. Arch. Dis. Child. 2005; 90: 284-7.

\section{Websites}

British Academy of Childhood Disability. https://www.bacdis.org.uk/

British Association for Community Child Health. http://www.bacch.org.uk

Disability Matters: e-learning to Inform and Inspire. https://www.disabilitymatters.org.uk/

Contact: For Families with Disabled Children. contact.org.uk

National Network of Parent Carer Forums. http://www.nnpcf.org.uk/ 


\section{Practice points}

- The diagnostic consultation should be a joint process between clinicians and parents/carers and involve relevant professionals most well-known to the family.

- Empathy, sensitivity and honesty through verbal and non-verbal communication should be conveyed throughout the diagnostic process. Information and explanation must be provided at all stages from investigations to diagnosis and subsequent management.

- From the start, emphasis needs to be placed on enhancing social outcomes for the child and family, in addition to understanding the impairments and planning interventions to improve function.

- A consistent and coordinated multidisciplinary approach is essential. This may be achieved through working across health, social care and education, with parent participation, and support from voluntary organisations, within the framework of Government initiatives and legislation.

- Engaging and empowering parents to work with professionals clinically, through research, and through service development can support parental adaptation and coping. 